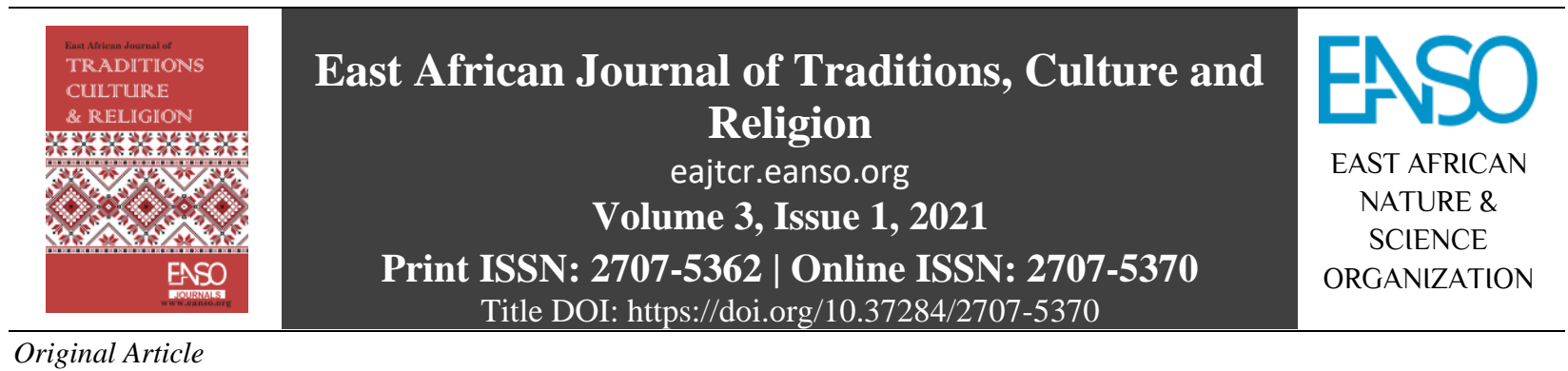

\title{
Right to Health: Polygyny and De Facto Polygyny may Increase Women's Vulnerability to HIV/AIDS in Tanzania
}

\author{
Fatuma A. Mgomba $^{1 *}$ \\ ${ }^{1}$ Institute of Judicial Administration Lushoto. P. O. Box 20, Lushoto, Tanzania \\ *Author for Correspondence Email: mgomba@gmail.com. \\ * ORCID: https://orcid.org/0000-0003-3193-1329.
}

Article DOI: https://doi.org/10.37284/eajtcr.3.1.293

Date Published:

10 March 2021

\section{ABSTRACT}

The world continues to faced many challenges both social and economic as a

Keywords: result of HIV/AIDS. Women in Tanzania and the world at large are among the most vulnerable population to HIV infection. Some of the communities to this Culture, day are starved of the critical information about the scourge as a result of the Polygyny, contradictions which emerge between the national laws (i.e., customary law) and married women, Marriage, Small Houses and international laws. This study aimed primarily at ascertaining the issues of whether polygynous marriage/small house are perceived to expose married women to the high risk of HIV/AIDS. Simple random sampling technique was HIV/AID. used to select rural and urban married men/women, especially among those living in polygamous and monogamous marriages and unmarried women who are in relations with married men (small house) at Lushoto in Tanzania. The study noted that married women are at risk of HIV/AIDS when their husbands practice de facto polygyny. As a result of the legal disparities between international laws and national law (i.e., customary law), polygynous marriage/small house exposes married women to a high risk of HIV/AIDS. The international community needs to come up with a standpoint that compels member nations of different cultural practices to ensure that women are not exposed to HIV/AIDS. HIV/AIDS is a reality and dissemination of information to all people should be considered a human right regardless of the different cultural practices. To this end, thousands of married women in polygamous and monogamous marriages are at risk of the scourge in Tanzania in particular and the world in general.

\section{APA CITATION}

Mgomba, A. F, (2021). Right to Health: Polygyny and De Facto Polygyny may Increase Women's Vulnerability to HIV/AIDS in Tanzania. East African Journal of Traditions, Culture and Religion, 3(1), 1-11. https://doi.org/10.37284/eajtcr.3.1.293 


\section{CHICAGO CITATION}

Mgomba, A Fatuma. 2021. "Right to Health: Polygyny and De Facto Polygyny may Increase Women's Vulnerability to HIV/AIDS in Tanzania". East African Journal of Traditions, Culture and Religion 3 (1), 1-11. https://doi.org/10.37284/eajtcr.3.1. 293

\section{HARVARD CITATION}

Mgomba, A. F.,(2021) "Right to Health: Polygyny and De Facto Polygyny may Increase Women's Vulnerability to HIV/AIDS in Tanzania", East African Journal of Traditions, Culture and Religion, 3(1), pp. 1-11. doi: 10.37284/eajtcr.3.1. 293.

\section{IEEE CITATION}

A. F. Mgomba, "Right to Health: Polygyny and De Facto Polygyny may Increase Women's Vulnerability to HIV/AIDS in Tanzania", EAJTCR, vol. 3, no. 1, pp. 1-11, Oct. 2021.

\section{MLA CITATION}

Mgomba, A Fatuma . "Right to Health: Polygyny and De Facto Polygyny may Increase Women's Vulnerability to HIV/AIDS in Tanzania." East African Journal of Traditions, Culture and Religion, Vol. 3, no. 1, Oct. 2020, pp. 1-11, doi:10.37284/eajtcr.3.1. 293.

\section{INTRODUCTION}

Polygyny is the practice of one man having more than one wife at one time. Moreover, we need to correct a common mistake in referring to polygyny as polygamy. Polygamy is the practice of having more than one husband or wife at the same time. Polygyny is the form of marriage practised in Africa and not polygamy. Traditionally, most Tanzanian societies have practised a custom of polygyny. This custom allows a man to have as many wives as he can support. These wives were married according to local custom and they were all legal in the understanding of the local world-view. Such a practice was not considered evil or immoral/sinful until the Christian missionaries arrived in Tanganyika. Even after the arrival of Christian, polygyny is still practised and valued based on cultural and religious points of view.

Polygyny as a cultural practice is attached with many socio-economic and political justifications. Socially, polygyny in the traditional societies had the greater merit of enabling most women to marry and have children. Since there were more marriable women than men because the women married at an earlier age and lived longer. Also, women tended to outnumber men because women are generally tougher than men. Moreover, men tended to engage in dangerous or fatal activities such as wars and hunting. In agricultural societies, human labour was essential and therefore, polygyny provided more hands to work in the fields and produce more food or more cash crops for sale. Thus, polygyny produced wealth, at least for the man as well as the whole group, which the patriarch supported. In political terms, the more wives one had, the more political alliances one could form, and therefore, become a very powerful power broker and effective politician or tribal leader, chief or king. Therefore, polygynous was the acceptable form of marriage in Tanzania prior to the arrival of the colonisers (Christianity and Arab/ Muslims).

\section{Historical Context and Background}

Tanzania like other former colonial states has a legal pluralism system such as customary law, Islamic law and general law applicable to personal issues. The general law is made up of legislation and Britain common law and since it is documented, there is generally little difficulty in determining its contents. Customary law on the other hand is "living law" composed of the laws and customs of the indigenous people (matrilineal and patrilineal societies). Matrilineal customary law and some patrilineal customary laws are not recorded and their contents are in the minds and practices of the people it governs; therefore, is fluid and open to interpretation. The Islamic law is the law according to the Muslim faith and as interpreted from the Quran as the main source of it and other sources like Sunna, hadith of the prophet, qiyas/ analogy and Ijma/consensus. Islamic law applies to Muslims only.

Before 1971, marriage in Tanzania was regulated by three different laws, i.e., written law for Christian, Islamic Law for Muslims and customary law for 
African indigenous/members of different communities. Besides customary laws, Islamic religions allow a man to marry up to four wives provided he can treat them equally. In 1971, the Tanzania government enacted a comprehensive law to govern and regulate all issues relating to marriage. The Law of Marriage Act of 1971 (hereinafter referred to as LMA) was enacted with the view of unifying and harmonising the thenexisting multiple regimes of the law of marriage. It aimed at bringing the law of marriage into accord with TANU aspirations of fostering equality, individual dignity, freedom and respect to the people; to provide for freedom of marriage and equal recognition of all marriage however celebrated, whether it be a Christian, Islamic, Civil or Customary. The LMA incorporated customary and religious marriage into a uniform marriage Act, giving both marriages state sanction and subjecting them to state regulations. This is to the effect that all marriages must be contracted and dissolved by the state. As a result, two types of marriage are existing; marriage may be polygamous/potentially polygamous or monogamous/intended to be monogamous. The LMA included polygynous marriage as a compromise to Islamic and Customary Law.

Polygynous marriage under the Act is defined to be a union of a man who may or may not be married and a woman who must be unmarried at the time of entering into marriage. Therefore, it is a form of marriage in which a man has more than one mate. The essence of the union is that it permits a man to have a plurality of wives. It will include instances in which the man lives with all the wives under the same roof and/or in the same homestead (patrilocality), as well as instances in which each wife has a separate home, and the man rotates from one home /house to the other (Mhoja, 2006). Therefore, a marriage contracted under Islamic and customary rites is presumed to be polygamous or potentially polygamous unless the contrary is proved.

Polygamous marriages continue in Tanzania but often in new and more problematic forms. Multiple unions in which a man has married more than one woman and lives with them on a live basis, but increasingly modern polygyny is taking other shapes. A man contracted in a monogamous marriage initiates an extramarital relationship with a girl/young female and considers her as his second wife (commonly referred to in the Swahili language as mchepuko (diversion) or nyumba ndogo (small house) while some writers refer to it as de facto polygyny or unofficial polygyny. Small houses/de facto polygyny is considered to be attuned to Tanzanians' modernity perceptions.

It is obvious that marriage in a patriarchal community is the backbone of society on which the whole definition of society lies. The desire to get married and stay married often overrides the risks of HIV/AIDS a woman faces in the marriage institution. For she is instructed to stay married, be obedient to her husband and never say no to his sexual demands regardless of his behaviour. The existence of a gender paradox is that men are most likely to have multiple partners, whereas women carry the most blame and suffers the greater stigma. This is aptly put by Patterson (2018) that on entering marriage with her husband as the first wife, she knew very well from customary law that the nature of marriages is polygamous and that no woman had any kind of sexual monopoly of the husband in the relationship. The same position applies to Muslim women save for a few requirements and exceptions.

There is no dispute that most married women in Tanzania have a lot of problems. Among other problems, their status is generally low in both the private and public spheres. Their low status is replicated within marriage, where they also occupy subservient positions. The situation and problems of women in contemporary society are born of developments in history that made men dominate over women. The beliefs over the years of the subordinated position of women have reinforced and perpetuated patriarchal oppression despite all the changes humans have known such as modernity. Paradoxically, all these factors mean that marriage has become a risk factor for many women. Patterson (2018) in his book points out that this may be particularly true for married women because of the social need to have children, the tendency of men to have most of their outside sexual partner in the early years of the marriage, and the risk of males straying during the wife's pregnancy or early postpartum period. 
A woman properly married in the home is at greater risk as far as HIV/AIDS is concerned, the reasons being power relation within the marriage (Patterson, 2018 , p. 24). Although the problems of women in society seem to be without end, real harm only comes when we do not attempt to uncover the truth about the real issues affecting the sexes. It is important to expose the problems affecting married women and try to overcome them or find solutions. Taking this in mind, it would be improper to regard married women and sex or related to it as not a critical sphere of study, especially in the HIV/AIDS era which is a matter of life or death. Therefore, this study on polygyny as a cultural and religious practice that increases women's vulnerability to HIV/AIDS will contribute towards exposing the effect of polygynous marriage and "small houses/mchepuko" to married women. This study also aims to see to what extent polygyny and extramarital relationship expose married women to the risk of HIV/AIDS.

\section{Statement of Problem}

Tanzania remains one of the few countries in the world where polygyny is still widely practised. Onefourth of Tanzanian women are involved in polygynous marriages (Howland \& Koenen, 2014, p. 10). Traditional polygyny is still common in rural areas of Tanzania due to moderation and westernisation. Polygyny practised in urban areas shifted to the modern style which is considered to be more adjusted to Tanzanians` perceptions of modernity. De facto polygyny is characterised as a relationship in which a man marries one wife and also form extra-legal domestic and sexual unions with other women (Howland \& Koenen, 2014).

Tanzanian scholars and women's rights activists have become less tolerant of the continued practice of polygamy. They argue that polygamy is rooted in gender and human inequality. They have called for further regulation or elimination of polygyny in Tanzania. Alternatively, some scholars support polygyny on sociobiological grounds, arguing that polygyny is a natural response to the fact that women outnumber men in Tanzania. Regardless of your stance on polygyny, the fact remains that it is still widely practised in Tanzania and is likely to increase HIV/AIDS spread.
Although many human rights groups and scholars advocate for the eradication of polygamy altogether, polygamy is still widely practised in Tanzania and is unlikely to decrease in the near future. Nonetheless, the government cannot sit and fold its hand and wait for polygamy to be "phased out" while a large portion of Tanzania's population remains without legal protection.

Numerous articles have been written about polygamous and HIV/AIDS, but only few scholars specifically examine the impact of polygyny in its new style of de facto/small house to the women health rights and protection which this article takes on board to realise how the Small house/de facto polygyny inherently increases women`s risk of contracting HIV/AIDS.

\section{Research Objective}

The primary objective of the study is to ascertain the issues of whether polygynous marriage/small houses are perceived to expose married women to a high risk of HIV/AIDS infection. Such an understanding would first determine if the practice is widespread and still relevant to the people. Another objective was to examine the real position of married women in relation to the right to control their sexuality. This objective was important, for it is the cultural and religious practice that was under investigation. The socialisation of women encourages stereotypic gender roles, which affects a woman's position in marriage.

\section{REVIEW OF LEGAL FRAMEWORK}

Human Rights and Legal Implication on Polygamy and HIV/AIDS

This research had to constantly make reference to the human rights frameworks for measuring compatibility to the cultural practices and right to health are under investigation. Human rights standards and principles provide the context within which the protection of women's rights can be measured and demanded. The Government of Tanzania is a signatory to a number of human rights instruments some of which specifically call for the treatment of women's rights as human rights, such as the Convention on the Elimination of All Forms of Discrimination against Women (CEDAW), which constitutes the international bill of rights for women. In developing a human rights compliance 
paradigm, the study analyses the law on protection from harmful cultural practices and marriage within the human rights framework in order to measure national compliance with human rights standards.

Basically, women's rights are human rights that are fundamental, inalienable, indivisible and inviolable and they should be guaranteed and protected. Some of these women's rights are the rights related to issues of marriage and self-protection and to be protected against sexually transmitted infectionsincluding HIV/AIDS. Various Human Rights Instruments lay down norms to be applied in marriage and health, covering issues relating to the rights of women. The key instruments and articles are as follows (paraphrased for clarity in some cases):

Article 5 of the Convention on the Elimination of All Forms of Discrimination Against Women (CEDAW) enjoins state parties to modify social and cultural practices with a view of eliminating prejudices and customary practices that are based on the superiority or inferiority of one sex over the other. Article 5 of the Protocol to the African Charter on Human and Peoples Rights on the Rights of Women in Africa (The Women's Protocol) directs state parties to prohibit and condemn harmful practices and it goes further to direct the state to inter alia provide information regarding harmful practices and protect women who are at risk of harmful practices. Article 4 of the Women's Protocol guarantees women's right to bodily integrity. Article 14 of the same guarantees women's right to health and this includes the right to control their fertility, the right to choose any method of contraception and the right to be protected from STI's including HIV/AIDS.

Article 14 of CEDAW also provides for the right to health. The right to health has also been provided under the preamble to the Constitution of the World Health Organization (constitution, 1946 preamble paragraph 2). Subsequently, Tanzania adopted Article 46 of the Universal Declaration of Human Rights (UDHR). The rights to culture and positive cultural values are provided for and recognised by Article 12 of the International Covenant on Economic, social, and Cultural Rights (ICESCR) and the African Charter on Human and People's Rights in Article 22 and Article 29(7) respectively.
Article 21 of the African Charter on the Rights and Welfare of the Child (ACRWC) enjoins States parties to eliminate harmful social and cultural practices affecting the welfare, dignity and normal growth and development of the child and prohibits the marriage of persons below the age of 18 years. Article 24 (3) of the Convention on the Rights of the Child (CRC) in guaranteeing the right to health directs State parties to abolish traditional practices prejudicial to children's health.

Tanzania has made some efforts to respond to the international rights and obligations, however, given the reservation and culture of silence regarding the express articulation of matters concerning sexuality and marriage. It is not surprising that most international human rights instruments, while they formally address rights that cover critical areas of human life and healthy, make no explicit commitments to the right to, or protection of, sexual activity, whether of oneself or between parties.

National Laws and Legal Implication on Polygyny and HIV/AIDS

In light of the applicability of international laws in Tanzania by virtue of its ratification, the applicability right to health as against harmful cultural practices (i.e., polygyny) has to be evaluated from a domestic perspective. There are few legal documents that debunk polygyny and HIV/AIDS and the right to health as hereunderexplained: -

The Constitution of the United Republic of Tanzania, 1977 Article 12 of the constitution recognises all human beings as equal and born free. Also, Article 13(1) of the Constitution states that "no person may be discriminated against on the grounds of sex". Article 19 states that every person has the right to the freedom of concise, faith and choice in matters of religion, including the freedom to change his religion. Constitution as mother law neither contains provision directly or impliedly address the issue of the right to protection against harmful cultural practices such as polygyny marriage nor the right to health.

The Law of Marriage Act, 1971 is among the legal instruments which govern and regulate all matters relating to marriage. Sections 10 (1) a \& b, (2) a and 25(1) of LMA is to the effect that marriage 
contracted under Islamic and customary rites are presumed to be polygamous or potentially polygamous unless the contrary is proved. The LMA embraces polygyny as a cultural and religious practice.

The HIV and AIDS (Prevention and Control) Act, 2007, Part II, IV and VII provide for public education and programme on HIV/AIDS, testing and counselling, the prohibition of discriminatory laws, policies and practice. Surprisingly, the Act does not prohibit acts or practice which expose women/ married women to HIV/AIDS such as polygamous, early marriage and female genital mutilation (FGM).

Despite the clarity of these legislations, the practice on the ground is different. The government has not seriously indicated ways to curb the situation, especially in this HIV/AIDS era. In terms of the national laws reviewed above, it is clear that there are incredible contradictions between each other.

Responding to the International Human Rights Instruments, the Government of Tanzania has enacted a number of laws and initiated administrative and policy measures to safeguard the rights to health of the woman. These include The National Policy on HIV/AIDS, which was adopted in November 2001 with the objective of providing a framework for leadership and coordination of the national multi-sectoral response to the HIV/AIDS epidemic. In February 2003, a National MultiSectoral Strategic Framework on HIV/AIDS for 2003-2007 was initiated and implemented by various sectors and institutions. The Health Policy of 1990 was revised in 2002 with a focus on people at risk and to encourage health centres to be more responsive to HIV/AIDS. Last but not least, the Women in Development Policy of 1992 was revised in 2000 and designated as the "Women and Gender Development Policy" to accommodate gender concerns and to promote the responsibilities of both parents in the care and development of children None of the above-reviewed policies directly address the issue of polygamous marriage in connection with HIV/AIDS. It is for this reason that the study intends to lobby policymakers to introduce policies to prevent the issue of polygamous marriage as the practice speedups HIV/AIDS.

\section{METHODOLOGY}

The main methodology used in this research is the women's law approach based on grounded theory as one of the research tools. Keeping in mind the principles of the methodological perspective, the main methods of data collection used in this study was the interview, group discussion, supplemented by desk research/library search. During the field study, different institutions were visited to collect views on the effect of polygamy in the era of HIV/AIDS. Besides those institutions, rural and urban women and men were interviewed individually or in groups through which different views were received related to polygamous marriages/de facto polygyny in the era of HIV/AIDS.

\section{DISCUSSION OF FINDINGS}

This part presents research findings, various views and opinions raised by the respondents during the research and discussion of finding on the other hand. Findings are discussed under two themes adopted as the analytical framework for presenting and discussing the field data from key informants. Respondents had differing views on the polygamous union as a cultural and religious practice increasing HIV/AIDS. There are those that explained that polygamous marriages and the so-called small houses are increasing women's vulnerability to HIV/AIDS infection. Some perceived that polygamous marriages are a means of controlling men from promiscuity hence reduce the possibility of HIV/AIDS to married women.

\section{Polygamy Increases Women's Vulnerability of HIV/AIDS}

Under this theme, research revealed that the majority of women interviewed were in monogamous marriages and their husbands have small houses. However, all women who were in monogamy and polygamous marriage were against polygamy and small houses. The main reason for the rejection/non-embracing of polygamy was that in this era of HIV /AIDS polygamy, de facto polygyny increases the chances of women being infected. The three women in monogamous marriages who were interviewed all indicated that it is due to the extramarital relation of their husband, which led to their HIV/AIDS infections. It is believed that polygamous marriages and HIV/AIDS 
are closely connected. There are various factors in polygamous marriages that contribute to women being HIV/AIDS.

Firstly, the right for women to decide about their own sexuality and to protect themselves against HIV \& AIDS needs to be an inalienable part of their right. This includes the right to use a condom. It is well known that women's vulnerability to HIV/AIDS increased not only out of physical vulnerability but also out of social practice. Men are empowered culturally to determine control over whether, when, where, with whom and how sex takes place. Findings revealed that in their societies, men have the power to determine whether to have sex or not and whether the sex is safe or unsafe. In addition, findings showed that according to the culture, women have a lower status than men, while men have a lead over relation. Socio-cultural norms that undervalue women also concurrently undervalue women's ability or power to control their sexuality and sexual wellbeing. As a result, choosing to have sex or use condoms has social meanings. Women suggest condom use can lead to violent confrontations.

In contrast to culture, Islamic religion allows men to have multiple sex partners. For men, in fact, cultural belief promotes variety in sexual partners as being essential to men's nature and that periodic sexual release is imperative for good health. HIV protection for married women appears to be very difficult and impossible. There was nearly unanimous agreement that it is a man's choice whether condoms are used or not. Suppose a woman suggested such things she would be suspected of infidelity and liable to be beaten. Refusing to have sex could result in similar violence or being sent away.

"You could not ask him to wear a condom, never," "women are forced in bed and they are not allowed to talk about sex," and in traditional ... you can't even discuss it with a man because he will say I paid BRIDE PRICE, WHY do you want to use plastic with me."

The use of condoms faces substantial obstacles in the African contexts in general and particularly in marriages. First of all, socially and culturally, the balance of control obviously lies with the man while women's bargaining power is weak. Married women cannot negotiate the use of condoms because asking their husband to use condoms is either interpreted as an accusation that he is promiscuous and/or has AIDS or is tantamount to a confession that the wife is promiscuous or has AIDS. The story of one SS speaks loud and clear about how the woman is powerless in negotiating safer sex within a marriage. She said:

"It is not only a taboo, but it is very difficult to negotiate the use of condoms within marriage. Under our customs, if a woman suggests the use of condoms, a man always thinks that his wife is not faithful. Also, it is taboo for a woman to refuse her husband's sex advance."

Besides, most men with so-called small houses are engaging with very young females or girls who are sexually active. Old men fail to satisfy these young female's sexual desires. Unsatisfactory sexual relationships forced these young females to find other men. On the other hand, these young women's decision to engage with the married man/old man is purely due to economic reasons and not "true love". As a result, they have other permanent young boyfriends. The following case history related to a wife in a monogamous marriage illustrated how a small house led to her HIV infection.

"My husband started to come back home very late at night... I suspected him of having affairs with another woman. But when I became aware that he was serious with the mchepuko 'small house', she was already pregnant for him. ... One year later, I heard he was suffering from tuberculosis (TB) and when he went for testing, he was found HIV positive. I went for tests in 2017 and I was also found HIV Positive..."

The research also revealed that some polygamous marriages originated from small houses. It is not usual for men to use condoms in a small house. This is proven by the fact that the second wife was taken after having been impregnated. In relation to polygamy, the problem arises because the second and subsequent wives are very young and when the husband fails to meet their sexual desires, the women may be tempted to have extramarital affairs. This possibility in the face of AIDS is very scary and might result in the disease spreading to innocent older wife/wives. 
Also, condoms directly conflicting with the goal of fertility and this are opposed by both traditional norms and religion. Traditionally, marriage is regarded as an institution of procreation, so the use of condoms is unacceptable because of its contraceptive effect. As one respondent pointed out that it is impossible to relate to the use of condoms and reproduction. One respondent said that "how would you relate the use of condoms and reproduction?"

Lastly, misinformation about condoms leads women to assume that they may be harmful. Most rural women believe that viruses are attached to the condom and therefore, condoms are harmful to their health. Morally, a woman who talks about condoms is considered to be morally loose. Secondly, Women's vulnerability to HIV/AIDS infection is increased by economic and cultural factors that place them at a disadvantage within relationships, the family, the economy and society at large. Women's economic dependence on men, their high poverty levels and lack of access to opportunities and resources contribute to their vulnerability to HIV/AIDS infection. Because of the economic dependence on men, women are unable to control their lives and protect themselves against HIV infection. This is because the men can withdraw economic support if the women refuse to do as they want. Cultural expectations and practices were also found to contribute to women's vulnerability to HIV/AIDS. Society expects women to be subordinate and submissive but allows men to have multiple sexual partners, which exposes women to HIV infection.

Women who are informed and economically independent are more able to control their sexual interactions. For example, some market women whose partners depend upon their earning are able to prevail upon them to use condoms. Similarly, well paid professional women may choose between celibacy and a partner who uses condoms. However, given the strong socialisation of females/girls for obedience to men, many women remain psychologically bound, although they are aware of the risk. Some may use denial to avoid the feeling of powerlessness.

Thirdly, Women fail to control their sexuality due to socialisation. In terms of married women controlling their sexuality, the research showed that under either type of marriage, married women could not control their sexuality. This is because, before marriage, they are taught not to deny their husbands' sexual advances and they believe that it is taboo to deny sexual advance when married. Married women, according to their culture are required to submit to every sexual request by their partner. However, in polygamous marriages, the situation is a bit worse due to the competitive nature of the relationship between the co-wives, as pointed out by one respondent:

"Under polygamous marriage, it is not possible for a woman to control her sexual right because I want my husband to be available all the time. So, rejecting his sexual advance means I allow him to go to another wife."

Data finding shows that women's limited power means that, although basic information on HIV/AIDS is available, this knowledge does not assist them in making the decision to avoid risky sexual behaviour. Because under their culture women cannot deny their husbands' sex advance or suggest the use of a condom. One woman said during the interview that:

"...the woman also is not allowed to refuse the husband's sex. It is a taboo for a woman to refuse her husband's sex advances".

The female vulnerability to HIV/AIDS-related to the above-discussed views is the effects of patriarchy on law, social and economic systems. This robs them of their power to make decisions regarding their sexuality and reproduction. Hence, that place control of these decisions with husband and elder male family members increasing women's vulnerability to HIV.

In all cases, respondents explained that polygamous marriages and small houses are increasing women's vulnerability to HIV/AIDS infection due to the fact that there is variation in power between spouses. Married women cannot refuse sexual advances or negotiate the use of condoms with her husband due to traditional and cultural reasons, such as the husband paid the bride price/dowry/Mahari for her, or it is taboo for the woman to discuss sexual issues with her husband. These respondents' views on polygamous/ small houses were that it is a cultural 
practice that is advantageous to men only. The respondents noted that although polygamy is a thing of the past, men still believe it is a practice that needs to be upheld. They totally resented polygamy and alleged that it no longer holds social rewards, especially in this era of HIV/AIDS. Polygamy acts as a vehicle that accelerates women's risk of HIV/AIDS.

Polygamous Marriage as Means of Controlling HIV/AIDS Infections

The study revealed an interesting paradox on how married women perceived polygamy in the era of HIV/AIDS. Most of the women in polygamous marriage interviewed were in favour of polygamous marriage. Their perception differs from those who believe that polygamous marriage increases women's risk of HIV/AIDS.

This is an interesting case of a second wife of four wives who is a businesswoman who perceived polygamous marriage as a means of controlling HIV/AIDS infections. She said:

"I am married to a polygamist. I am the second wife of four wives. I do not believe in the use of a condom because we trust each other and our religion does not believe in the use of condoms. I believe my husband cannot go outside marriage because we are four and we satisfy him."

Therefore, she strongly believes that polygynous marriage is a means of controlling men's promiscuity.

In terms of women's capacity to suggest the use of condoms with their husbands, they said married women cannot negotiate the use of condoms even if they suspect their husband is having an extramarital affair. As one respondent said,

"It is difficult to negotiate the use of condom or contraceptive methods within marriage. If a woman suggests the use of condoms, man always thinks that his wife is not faithful."

The study shows that it is difficult for a woman to initiate the use of condoms within marriage due to their religious and cultural beliefs. Condoms conflicting with the goal of fertility and are opposed by both traditional norms and Islamic religion.
Traditionally marriage is regarded as an institution of procreation, so the uses of condoms are unacceptable because of their contraceptive effect.

The study showed that polygamy is regarded as traditional /cultural and religious practices that control men's promiscuity behaviour and described it as the cultural and Islamic religious practice. All of them noted that polygamy in the era of HIV/AIDS plays a role in controlling HIV/AIDS infection because the husband will be satisfied with his wives, so it is not possible for him to find another woman outside of his wives.

\section{CONCLUSION}

Tanzania is one of the few countries where polygamy is still widely

practised. Although Tanzanians may receive full legal recognition for a polygamous

marriage through the LMA, polygamy is being transformed to include other unofficial

relationships, whereby men marry one woman according to the statutory law and also form extralegal domestic and sexual unions with other women. The research study found that polygamous marriages are still cultural and religious practices prevailing more in rural areas as compared to urban areas because in urban areas polygamous marriages have taken another form of "small houses". The majority of respondents in this study are absolutely in agreement that polygamy is increasing the vulnerability of women to HIV/AIDS. Their contentions are based on the fact that polygamy was designed by men for the purpose of benefiting themselves; however, nowadays it has lost its intrinsic value due to economic depression and HIV/AIDS pandemic. On the other hand, few respondents are definitely not in agreement that polygamy is a cultural practice that speeds up the transmission of HIV/AIDS. Their basis for the arguments that polygamy is a cultural practice practised by the forefathers, and so it is not good to disregard their culture. In terms of HIV/AIDS and polygamy, they argued that polygamy is one way of controlling HIV/AIDS.

In relation to the married women's right to control sexuality, all respondents virtually seemed to be in agreement that married women, especially in 
polygamous marriages are far from immune from the risk of HIV/AIDS for a variety of reasons: because their husbands infect them after receiving the virus from other sexual contacts; because they are unable to negotiate condom use; they cannot refuse sex, no matter how high the risk, because they are economically dependent upon their husband. The continuation of the marriage depends upon giving birth to children, making condoms unacceptable because of their contraceptive effect and asking their husband to use condoms is either interpreted as an accusation that he is promiscuous or has AIDS or is tantamount to a confession that the wife is promiscuous or has AIDS. These are many of the issues arising from women who are in an inferior position in marriage institutions.

A lot of contradictions emerged between male and female views, as well as urban and rural women on their perception of polygamy and HIV/AIDS. Therefore, it is difficult to draw a general conclusion. However, what was ascertained from the majority of the respondents was that polygamy exposed women to HIV/AIDS. Although it is not possible to draw a definitive and general conclusion from micro studies like this one, it can still be argued that this kind of analysis challenges us to begin to look deeper at some cultural practices whose continuation is one basis of tradition/culture. Cultural practices are supposed to suit a particular environment and social-economic development; this implies that whatever is considered custom/cultural practice of any group has to change with its people (Dengu-Zvogbo et al., 1994). Further analysis of this study shows that women are somehow becoming at least conscious of the inferior status that is accorded within marriage and their risk to HIV/AIDS.

Co-wives and sexual partners in polygynous marriages and unofficial polygyny live in fear of becoming HIV - infected as they often have diminutive control over the sexual behaviour of other members of the polygynous family (Mswela, 2009). It is indisputable that polygynous marriages create a fertile environment for the spread of HIV/AIDS (Epstein, 2005). Because the practice of small houses creates a network of simultaneous connecting sexually active people not only to one another but also to the partners of their partners and to the partners of those partners, and so on.
Polygamous men generally seek out young women, even as they themselves age. In this way, the traditional polygyny and small houses may spread the virus from one generation to the next and contributes to the rise of infection levels.

Legislation to govern and regulate polygynous marriage and empower women to leave unhealthy marriages could be active in hindering or supporting initiatives to deal with the HIV/AIDS epidemic (Howland \& Koenen, 2014). Within the context of polygynous marriages, the overwhelming impacts of HIV/AIDS, widespread poverty, and increasing competition require a legislative solution. Law reform is not a complete solution to the HIV epidemic among women, but it is a necessary and often neglected step. In the past, very few women complained against polygamy. Today more do. Tomorrow I hope more will do

\section{RECOMMENDATIONS}

Recommendations are proposed actions for various actors who emerged with a role to play in polygamous marriage/ small houses. On the basis of the foregoing analyses, the main recommendation of this study is as follows: -

Firstly, polygamy as a cultural aspect; the more that people call for change in the norms or practices of their own culture, the stronger the case for change becomes. It is vital for campaigners to invoke as many people within the community as they can be to participate in challenging the polygamous marriages and the so-called small houses (Butegwa, 2002). Diversity may also be important, as it would indicate that the demands within the community are widespread and cut across gender, individual, or sectarian issues within the culture.

Secondly, information and education on sexuality and HIVAIDS should be gender-specific and explicitly accessible for women, men, boys and girls. A possible long-term strategy geared at sensitising the public could be created by mobilisation of massive information and communication campaign or a grassroots' popular education programme on the effect of polygamy in the era of HIV/AIDS. Citizens who are involved and well-informed serve as the major foundation stones of a human rights platform. 
Thirdly, to promote gender equality, imbalance gender relations should be addressed comprehensively through a multi-media campaign on underlying imbalances in gender roles and norms. Respect for women and girls should be promoted and their equal role in marital and other relationships emphasised. During pre-marriage counselling, women should no longer be advised to submit themselves to their husbands and instead, gender equality and couple counselling should be promoted.

Fourthly, law reform manifests a number of factors that affect the implementation of human rights, such as the level and equality of political commitment to the implementation of the administrative, educational and other policies. Nonetheless, legal protection is particularly important in the judicial enforcement of the rights as a legal entitlement. This sustains the efficacy and credibility of all other mechanisms and processes, the development and application of operational definitions of each human right and the mediation of competing claims of rights (An-Na`im \& Hammond, 2005).

Thus, in light of empirical evidence from the HIV positive married women stories, it is vital to amend our laws in order to internally effectuate the principles of equality and non-discrimination and also to present evidence of practice to the contrary. To achieve concrete legal reform, changes must be made in all areas of the law, starting with the constitution. It is important that the constitution clearly addresses the continuing tension between protected rights and preserved cultures and indicates which is to have priority in the event of a conflict. The constitution of the Republic of Uganda, 1995, may serve as a useful guide in this aspect.

\section{REFERENCES}

An-Na im, A. \& Hammond, J. (2005). Cultural transformation and human rights in African society. In An-Na`im, A. (ed), Cultural Transformations and Human Rights in Africa. London, UK: Zed Books Ltd.

Butegwa, F. (2002). Mediating culture and human rights in favour of land rights for women in Africa. In An-Na'Im, A. (ed) 2002, Culture Transformation and Human Rights in Africa. London, UK: Zed Books Ltd.
Dengu-Zvogbo, K., Donzwa, B. R., Gwaunza, E. C., Kazembe, J. L., Ncube, W., \& Stewart, J. E. (1994). inheritance in zimbabwe: Law, customs and practice. Sapes, Harare: WLWS-Zimbabwe.

Epstein, H. (2005). God and the fight against AIDS. New York Review of Books, 52(7), 47-51.

Howland, R. J., \& Koenen, A. (2014). Divorce and polygamy in Tanzania. Social Justice, 15.

Mhoja, M. E. (2006). Child-widows silenced and unheard: Human rights sufferers in Tanzania. Children's Dignity Forum.

Mswela, M. (2009). Cultural practices and HIV in South Africa: a legal perspective. Potchefstroom Electronic Law Journal/Potchefstroomse Elektroniese Regsblad, 12(4).

Patterson, A. S. (Ed.). (2018). The African state and the AIDS crisis. Routledge. 